-Review·

\title{
Dopaminergic modulation of synaptic plasticity in rat prefrontal neurons
}

\author{
Satoru Otani ${ }^{1,2}$, Jing $\mathrm{Bai}^{2}$, Kevin Blot $^{3}$ \\ ${ }^{1}$ Center for Medical Education, Faculty of Health Sciences, Ryotokuji University, Chiba, Japan \\ ${ }^{2}$ Chinese Medicine Research Laboratory, Juntendo University Medical School, Tokyo, Japan \\ ${ }^{3}$ Pathophysiology Department, University of Paris 6, Paris, France \\ Corresponding author: Satoru Otani. E-mail: otani@ryotokuji-u.ac.jp \\ (c) Shanghai Institutes for Biological Sciences, CAS and Springer-Verlag Berlin Heidelberg 2015
}

The prefrontal cortex (PFC) is thought to store the traces for a type of long-term memory - the abstract memory that determines the temporal structure of behavior often termed a "rule" or "strategy". Long-term synaptic plasticity might serve as an underlying cellular mechanism for this type of memory. We therefore studied the induction of synaptic plasticity in rat PFC neurons, maintained in vitro, with special emphasis on the functionally important neuromodulator dopamine. First, the induction of long-term potentiation (LTP) was facilitated in the presence of tonic/background dopamine in the bath, and the dose-dependency of this background dopamine followed an "inverted-U" function, where too high or too low dopamine levels could not facilitate LTP. Second, the induction of long-term depression (LTD) by low-frequency stimuli appeared to be independent of background dopamine, but required endogenous, phasically-released dopamine during the stimuli. Blockade of dopamine receptors during the stimuli and exaggeration of the effect of this endogenouslyreleased dopamine by inhibition of dopamine transporter activity both blocked LTD. Thus, LTD induction also followed an inverted-U function in its dopamine-dependency. We conclude that PFC synaptic plasticity is powerfully modulated by dopamine through inverted-U-shaped dose-dependency.

Keywords: prefrontal cortex; synaptic plasticity; long-term memory

\section{Introduction to Synaptic Plasticity and the Prefrontal Cortex}

The prefrontal cortex (PFC), the cortical area most developed in humans, is known to serve for higher cognitive or executive functions ${ }^{[1]}$. Deficits in the PFC are thought to underlie the cognitive disturbances seen in psychiatric disorders including schizophrenia, depression, drug addiction, and attention deficit and hyperactivity disorder ${ }^{[2]}$. Therefore, understanding the physiological and pathophysiological bases of PFC neuronal function helps to understand the cellular basis of higher cognitive abilities and their disturbance. In this regard, it should be noted that the PFC receives innervation from dopaminergic fibers from the ventral tegmental area ${ }^{[3]}$, and that rat PFC neurons express dopamine (DA) receptors in different layers ${ }^{[4]}$. This dopaminergic projection is important for diverse cognitive functions including working memory, goal-direction, and other executive functions ${ }^{[5,6]}$.

Working memory has attracted much attention as a major example of PFC executive functions. Indeed, revealing the cellular basis of working memory is a major accomplishment of neuroscience research ${ }^{[7]}$. The reasons that working memory research attracts attention are that working memory is clearly a critical component of higher mental activity and that its impairment is a core feature of the cognitive symptoms of schizophrenia ${ }^{[8]}$.

It is well known that working memory is the short-term maintenance of a retrieved/acquired memory about facts and objects. Given the tight association between this short- 
term memory and PFC function, the role of the PFC in longterm memory has often been overlooked. But it is clear that the functions of the PFC include a long-term memory component ${ }^{[1]}$, and the cognitive symptoms of schizophrenia also include deficits in long-term memory ${ }^{[9]}$.

The long-term memory we suggest to be attributable to the PFC is a higher-order, abstract memory labelled as "temporal organization of behavior", "rule", "strategy", or "planning"; that is, a memory that determines the sequence of outputs of concrete actions/ideas ${ }^{[2]}$. We propose that the traces for this type of long-term memory are at least partly stored in neurons of the PFC in the form of long-term synaptic plasticity ${ }^{[2]}$. Indeed, injection of a protein synthesis inhibitor known to block the maintenance of synaptic plasticity into the prelimbic area (rodent PFC) severely impairs the acquisition of goal-directed action sequences ${ }^{[10]}$.

Based on this important relationship between longterm memory and the PFC, here we review long-term synaptic plasticity, i.e. long-term potentiation (LTP) and long-term depression (LTD), two of the cellular mechanisms for memory encoding and storage, in rodent PFC neurons (the prelimbic area). Our particular interest is the induction mechanisms of LTP and LTD with special emphasis on DA, an important neuromodulator of PFC function.

\section{LTP in PFC Neurons and Dopamine}

\section{LTP and Background Dopamine}

LTP is typically induced by trains of high-frequency stimuli delivered to presynaptic fibers. So, we applied stimuli at $50 \mathrm{~Hz}$ (4 or 6 trains of 100 pulses, delivered at 10-s intervals) to layer I-II presynaptic fibers in rat PFC slices, and monitored the changes in the excitatory postsynaptic potentials (EPSPs) recorded from layer $V$ pyramidal neurons. The frequency $50 \mathrm{~Hz}$ is within the range of functionally important $y$-band activity in the PFC ${ }^{[11]}$. In addition, all main experiments were conducted in the presence of the GABA-A receptor antagonist bicuculline so that inhibitory postsynaptic potentials were largely eliminated.

We found that while hippocampal neurons readily show LTP after such $50-\mathrm{Hz}$ stimulation, in PFC neurons, the stimuli either induce no plasticity (trains delivered 4 times; Fig. 1A) or induce LTD (delivered 6 times; Fig. 1B). These results are in contrast to the result obtained in the rat
PFC in vivo, where high-frequency afferent stimuli always induce $L T P^{[12]}$.

An important difference between in vivo and in vitro preparations is that in the latter, the extracellular DA level is very low, perhaps to a degree that is non-physiological. In the PFC in vivo, in contrast, background DA is maintained even under anesthesia by the tonic spontaneous activity of midbrain dopaminergic neurons ${ }^{[13]}$. Therefore, in an attempt to mimic the in vivo condition in the slice preparation, we added to the bathing medium a low concentration of DA ( $3 \mu \mathrm{mol} / \mathrm{L}$ ) as background, continuously for $40 \mathrm{~min}$ before the delivery of the identical $50-\mathrm{Hz}$ stimulation. Under this condition, the delivery of trains 4 and 6 times both induced clear LTP (Fig 1C, D) ${ }^{[14,15]}$. Thus, the background DA secured the induction of LTP.

The concentration of $3 \mu \mathrm{mol} / \mathrm{L}$ was chosen because it is about the lowest concentration of exogenous DA that elicits detectable changes in the EPSP under our recording condition (i.e. slight reductions or slight augmentations of the responses). In behaving animals, however, the DA concentration, in the nucleus accumbens for example, estimated by voltammetry is $\sim 1 \mu \mathrm{mol} / \mathrm{L}$ or less, even at the peak ${ }^{[16]}$. Compared with this, $3 \mu \mathrm{mol} / \mathrm{L}$ may appear high. However, the probe used in the voltammetry has a diameter of $\leq 10 \mu \mathrm{m}$, which is as large as the diameter of a cell body. The real concentration near a synapse is likely to be much higher, possibly reaching the $\mathrm{mmol} / \mathrm{L}$ range ${ }^{[17]}$.

\section{Constraints on LTP Facilitation by Background Dopamine}

We discovered two functionally important constraints in the LTP facilitation by background DA described above. First, the level of the background DA has to be within a certain range: too high $(10 \mu \mathrm{mol} / \mathrm{L})$ or too low $(1 \mu \mathrm{mol} /$ $L)$ a concentration does not facilitate $\operatorname{LTP}^{[17]}$. This finding indicates that the dose-dependency of LTP induction on the background DA follows an inverted-U dose-response curve, reminiscent of the relationship between the level of DA in the PFC and its modulatory action on PFC-dependent cognitive functions ${ }^{[2,6]}$. Second, the background DA, even at an appropriate level ( $3 \mu \mathrm{mol} / \mathrm{L}$ in our case), has to be present long enough to facilitate LTP. Thus, the $3 \mu \mathrm{mol} / \mathrm{L}$ DA facilitated LTP after 40 min bath-application, but not after $12.5 \mathrm{~min}^{[14]}$. This is reminiscent of the fact that background DA is continuously present in the PFC in vivo. In addition, 

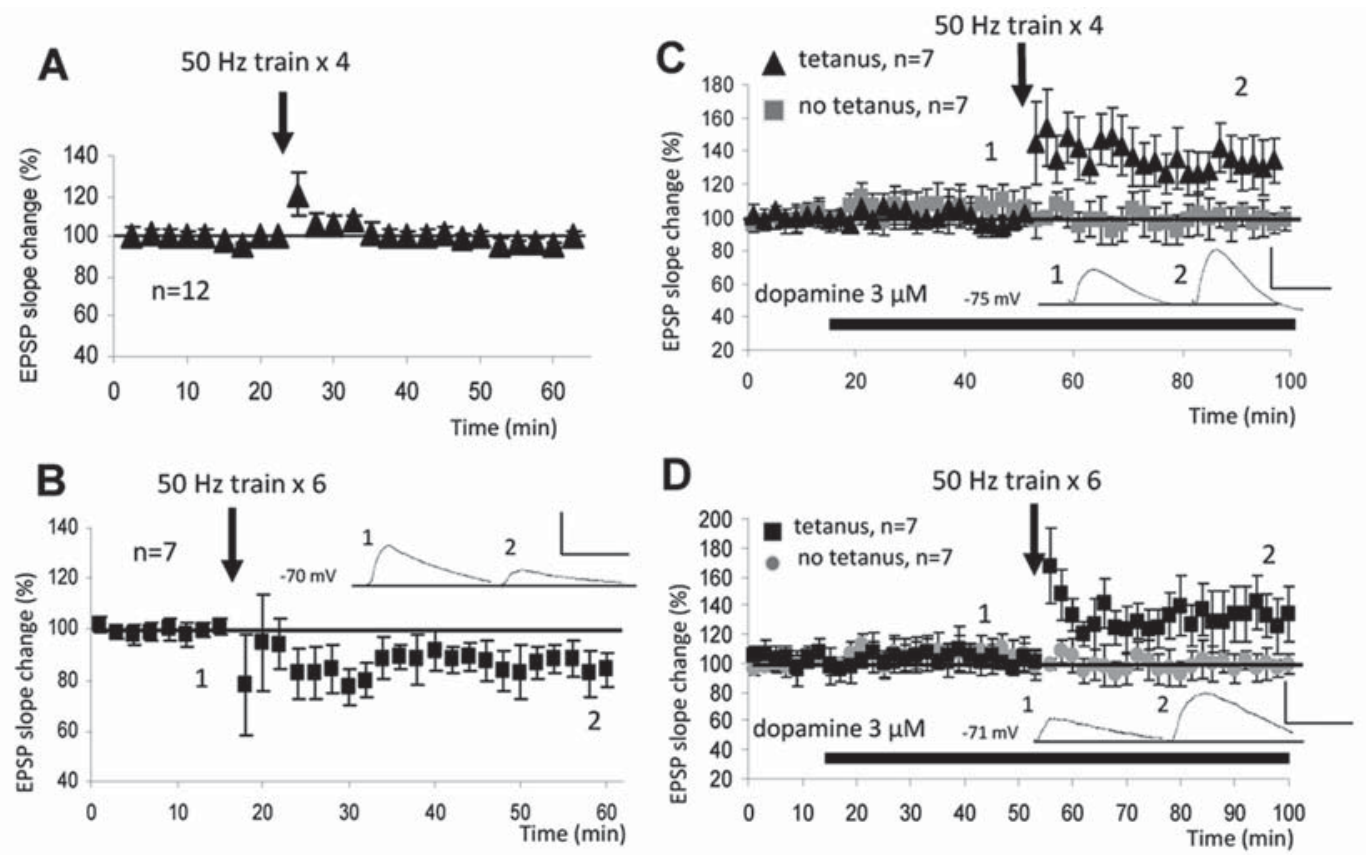

Fig. 1. Effect of high-frequency stimuli on the EPSP recorded from layer V pyramidal neurons in rat prelimbic cortex slices. A. Delivery of 50-Hz stimuli (100 pulses, 4 trains at 10-sec intervals) to layer I-Il presynaptic fibers in prelimbic slices induces no lasting changes in the EPSP. B. The stimuli were delivered 6 times. In this case, clear LTD is induced. The insets are the averaged EPSP recorded just before (1) and 40 min after stimulation (2). C. Delivery of $\mathbf{5 0}-\mathrm{Hz}$ stimuli 4 times (as in A) after $\mathbf{4 0}$ min perfusion with $3 \mu \mathrm{mol} / \mathrm{L}$ background dopamine results in LTP (black triangles). The insets are the averaged EPSP recorded just before (1) and 40 min after stimulation (2). The 3- $\mu \mathrm{mol} / \mathrm{L}$ background dopamine itself does not modify the EPSP (grey squares). D. Delivery of 50-Hz stimuli 6 times (as in B) after 40 min perfusion with $3 \mu \mathrm{mol} / \mathrm{L}$ background dopamine converts the LTD to LTP (black squares). The insets are the averaged EPSP recorded just before (1) and $40 \mathrm{~min}$ after stimulation (2). The 3- $\mu \mathrm{mol} / \mathrm{L}$ background dopamine itself does not modify the EPSP (grey circles). Scales in B-D: vertical $10 \mathrm{mV}$, horizontal $50 \mathrm{~ms}$. Adapted from Kolomiets et al. (2009) ${ }^{[15]}$, with permission.

DA acts on both D1 and D2 receptors to facilitate LTP ${ }^{[15]}$.

\section{Mechanisms Underlying the Action of Back- ground Dopamine}

The above results indicate that LTP is induced in the PFC only when the physiological conditions are mimicked: thus, an appropriate level of background DA $(3 \mu \mathrm{mol} / \mathrm{L}$ in our case) must be present for a certain time (40 min in our case) in order to successfully facilitate LTP.

What, then, is the molecular mechanism underlying this DA effect? Our analysis indicated that it is the activation of extracellular signal-regulated kinases (ERK1/2). We first confirmed that LTP requires the postsynaptic activation of ERK ${ }^{[15]}$. We then quantified the phosphorylated ERK level in the PFC by western blot analysis and found that ERK phosphorylation increases slowly in the presence of $3 \mu \mathrm{mol} / \mathrm{LDA}^{[15]}$. More precisely, a significant increase in the phosphorylated ERK occurs after 40 min perfusion
(LTP condition) but not after 12.5 min perfusion (non-LTP condition). Equally, in two other non-LTP conditions (40 min perfusion of 1 or $10 \mu \mathrm{mol} / \mathrm{L}$ DA) no increased ERK phosphorylation is seen. Moreover, under the condition where the increased ERK phosphorylation by 40-min perfusion of $3 \mu \mathrm{mol} / \mathrm{L}$ DA is lowered to the control level by a brief bath-application of ERK inhibitor PD98059, LTP induction is also blocked, suggesting a causal relation between the slow increase of ERK phosphorylation and LTP induction.

Apart from the above inverted-U dose-response activation of ERK, however, little is known as to how the background DA regulates LTP through the inverted $U$-fashion. For example, background DA does not affect $\mathrm{N}$-methyl-D-aspartate receptor-mediated synaptic transmission ${ }^{[15]}$, unlike the previous report ${ }^{[18]}$. One candidate for the underlying mechanism is a dose-dependent, D1- 
mediated increase of neuronal excitability ${ }^{[19]}$. Indeed, background DA does enhance the postsynaptic depolarization during LTP-inducing high-frequency input ${ }^{[15]}$. However, this enhancement does not follow an inverted-U curve, since 1 or $10 \mu \mathrm{mol} / \mathrm{L}$ DA, which does not facilitate LTP, still enhances the depolarization ${ }^{[15]}$. Also, unlike the report by Chen et al. ${ }^{[19]}$, this enhanced postsynaptic depolarization persists in the presence of the ERK inhibitor PD98059 ${ }^{[15]}$. Thus, while it is likely that the enhanced postsynaptic depolarization by background DA contributes to the induction of DA-facilitated LTP, other cellular processes must co-exist to realize the inverted-U, dosedependent regulation of LTP.

\section{LTP and Phasic Dopamine}

As well as the tonic/background DA, which is maintained by the spontaneous, basal firing of DA neurons, eventrelated phasic release of DA, which is correlated with a transient, event-related high-frequency discharge of DA neurons in vivo, is functionally important ${ }^{[20]}$. This phasic DA, when occurring in temporal conjunction with glutamatergic synaptic activity, facilitates LTP in the PFC in vivo ${ }^{[12]}$. In our case, equally, the same conditioning stimuli activated both glutamatergic and dopaminergic axon terminals in PFC slices. The functional importance of this timing between dopaminergic and glutamatergic inputs has also been shown in a recent report by Yagishita et al. ${ }^{[21]}$ in striatal neurons. We thus also examined how phasic DA is involved in LTP induction in vitro.

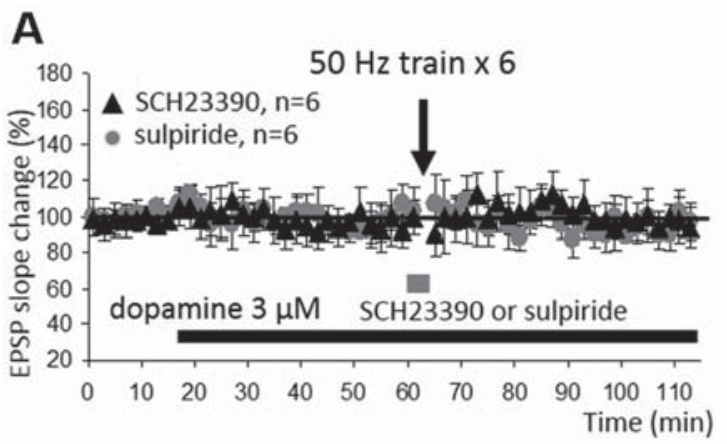

First, blockade of D1 or D2 receptors by the specific antagonist SCH23390 $(2 \mu \mathrm{mol} / \mathrm{L})$ or sulpiride $(20 \mu \mathrm{mol} / \mathrm{L})$, respectively, only during the delivery of $50-\mathrm{Hz}$ stimulation, reliably blocks LTP in the presence of $3 \mu \mathrm{mol} / \mathrm{L}$ background DA (Fig. 2A). This indicates that endogenous, stimulusevoked phasic release of DA is required for LTP (note that there is a remote possibility that the brief absence of tonic DA action while the antagonists are present causes the LTP blockade). In PFC slices, the axons of dopaminergic neurons are severed, but the residual axon terminals release DA upon repetitive stimulation and induce plasticity ${ }^{[22]}$. Indeed, the superficial layers of the rat PFC receive dopaminergic innervation ${ }^{[23]}$, and rat frontal pyramidal neuron dendrites co-express D1 and D2 receptors ${ }^{[4]}$. Second, the LTD induced by delivery of $50-\mathrm{Hz}$ stimulation 6 times in the absence of background DA (see Fig. 1B) is also blocked by $\mathrm{SCH} 23390$ or sulpiride (Fig. 2B), indicating that this LTD also depends on phasic endogenous DA. Note that in Fig. 2B, a small LTP appears when either D1 or D2 receptors are blocked. Such LTP does not occur when D1 and D2 receptors are simultaneously blocked ${ }^{[15]}$. This indicates that without background DA (an abnormal condition) an imbalance of stimulation between these two receptor classes can give rise to response potentiation through as yet unknown mechanisms.

Thus, the phasic DA released upon $50-\mathrm{Hz}$ stimulation can induce either LTP or LTD through the co-activation of D1 and D2 receptors, which might result in the synergistic

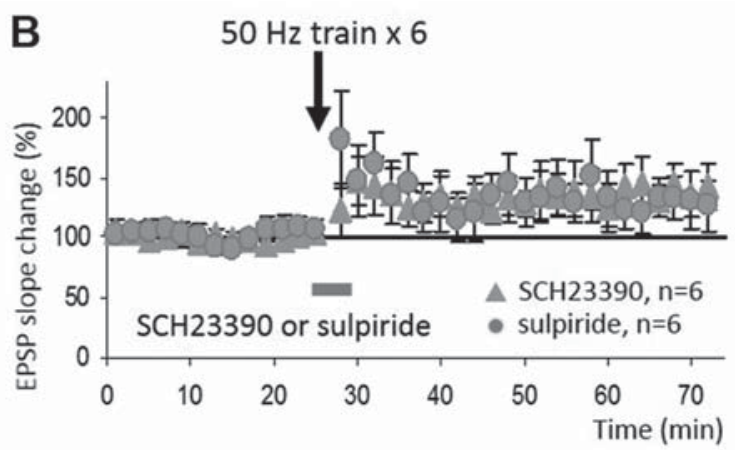

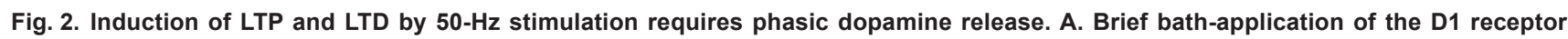
antagonist SCH23390 (2 $\mu \mathrm{mol} / \mathrm{L}$; black triangles) or the D2 receptor antagonist sulpiride (20 $\mu \mathrm{mol} / \mathrm{L}$; grey circles) during LTPinducing $50-\mathrm{Hz}$ stimulation (6 times) after 40 min perfusion with $3 \mu \mathrm{mol} / \mathrm{L}$ background dopamine (see Fig. 1D) blocks the induction of LTP. B. The identical application of SCH23390 or sulpiride as in A during LTD-inducing stimulation (delivery of 50-Hz stimulus train 6 times without background dopamine) blocks the induction of LTD. Adapted from Kolomiets et al. $(2009)^{[15]}$ with permission. 
activation of phospholipase $\mathrm{C}^{[4]}$. These opposite effects of DA suggest that its phasic release serves as a "trigger" for plasticity but it does not determine the direction of the plasticity (i.e. LTP or LTD); the direction of plasticity is determined by the level of background DA. Thus, when the level of background DA is appropriate $(3 \mu \mathrm{mol} / \mathrm{L}$ in our case), the phasic DA triggers LTP (Fig $1 \mathrm{C}, \mathrm{D})$; but when the level is low $(1 \mu \mathrm{mol} / \mathrm{L})$ or high $(10 \mu \mathrm{mol} / \mathrm{L})$, the phasic DA cannot trigger LTP. When the level is extremely low (absence of background DA in our case; see Fig. 1B), the same phasic DA now triggers LTD. Our additional data ${ }^{[14,24,25]}$ suggest that when the level of background DA is extremely high $(100 \mu \mathrm{mol} / \mathrm{L})$, the phasic DA also triggers LTD. These relationships between phasic and background DA in terms of plasticity induction are graphically presented in Figure 3.

\section{LTD in PFC Neurons and Dopamine}

\section{Induction of LTD by Low-Frequency Repetitive Stimuli}

In the PFC, the induction of LTD by low-frequency repetitive stimulation has been demonstrated in mouse brain slices ${ }^{[26]}$

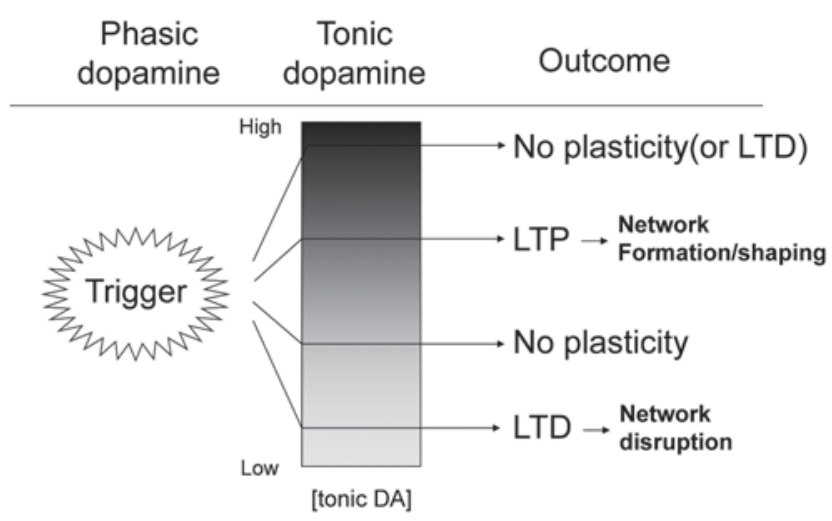

Fig. 3. Schematic representation of the relation between phasically-released dopamine upon high-frequency input and tonic/background dopamine in terms of plasticity induction in the PFC. The stimulus-evoked phasic dopamine serves as a "trigger" for plasticity, but does not determine the direction of plasticity. The direction (i.e. potentiation or depression) is determined by the level of tonic/background dopamine. The phasic dopamine only triggers LTP at appropriate levels of tonic/background dopamine. Under very low or very high levels of tonic/ background dopamine, the phasic dopamine triggers LTD, which we term as "aberrant LTD". Adapted from Goto et al. $(2010)^{[2]}$ with slight modifications. but had never been shown in rat preparations. Therefore, we first determined whether low-frequency stimuli $(3 \mathrm{~Hz}$ for $15 \mathrm{~min})^{[26]}$ delivered to layer I-II afferent fibers induces LTD in rat PFC slices. We found that the $3-\mathrm{Hz}$ stimulation successfully induces LTD of the EPSP (Fig. 4A) ${ }^{[27]}$, monitored in this case by an extracellular microelectrode in layers $1-\mathrm{II}^{[28]}$.

This LTD by $3 \mathrm{~Hz}$ stimulation was induced even in the presence of $3 \mu \mathrm{mol} / \mathrm{L}$ background DA (data not shown). This is in sharp contrast to the LTD induced by $50 \mathrm{~Hz}$, which converts to LTP when $3 \mu \mathrm{mol} / \mathrm{L}$ DA is added to the bath (Fig $1 B, D)$. This difference may indicate that LTD induced by 3 $\mathrm{Hz}$ stimulation is a physiologically relevant form of synaptic depression that persists in the presence of background $\mathrm{DA}^{[27]}$.

\section{Inhibition of Dopamine Transporter Activity and} LTD

LTD by $3 \mathrm{~Hz}$ stimuli is blocked by the D1 receptor antagonist $\mathrm{SCH} 23390(2 \mu \mathrm{mol} / \mathrm{L})$ or the $\mathrm{D} 2$ receptor antagonist sulpiride $(20 \mu \mathrm{mol} / \mathrm{L})$ applied during the $3 \mathrm{~Hz}$ stimulation (Fig. 4B1 and 4B2). Thus, this LTD depends on endogenously-released DA acting on both D1 and D2 receptors; that is, levels of receptor activation by phasicallyreleased DA that are too low are insufficient for LTD. Is this LTD then inhibited by levels of phasic DA that are too high, forming an inverted-U dose-response curve?

To test this possibility, we elevated the extracellular DA level by inhibiting the DA transporter (DAT) using selective blockers. Since the DAT is inhibited by cocaine, this study is also important with regard to the molecular mechanisms of drug addiction. Cocaine also inhibits the norepinephrine and serotonin transporters, but the reinstatement of cocaine addiction occurs specifically through the drug's action on the DAT in the PFC ${ }^{[29,30]}$.

From the functional aspect, the involvement of DAT inhibition in the PFC in the reinstatement of cocaine addiction predicts that LTD in the PFC would be impaired by DAT inhibitors. This is because reinstatement is the condition where behavioral flexibility is diminished by reexposure to cocaine so that the individual becomes unable to suppress the old goal-direction, i.e. cocaine-seeking. Since the main function of LTD in the PFC is to guarantee behavioral flexibility by suppressing old goal-directions ${ }^{[31]}$, the inhibition of DAT in the PFC, which diminishes behavioral flexibility, should inhibit LTD.

As predicted, the highly-selective DAT inhibitor GBR12909 (1-200 nmol/L) or GBR12935 (100 nmol/L), 
A

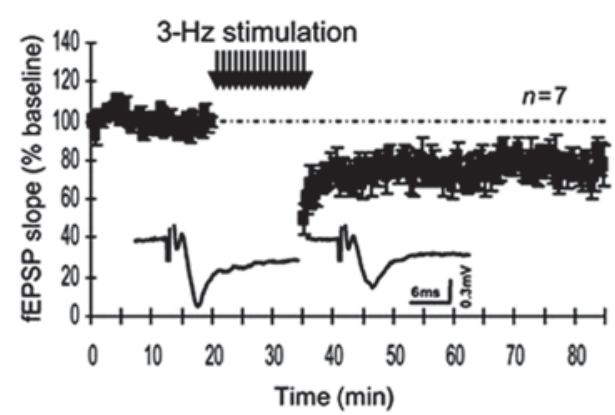

B2

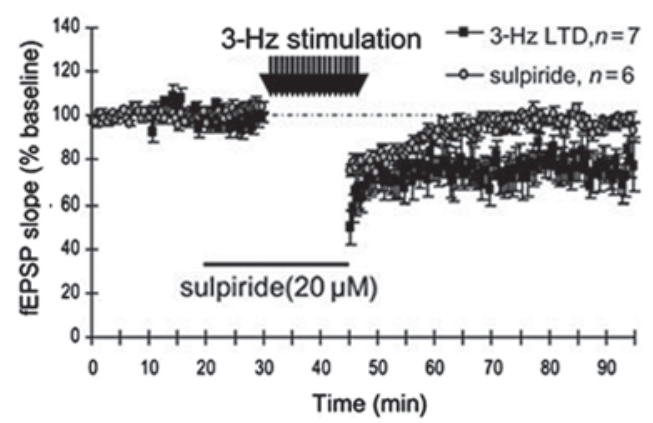

B1

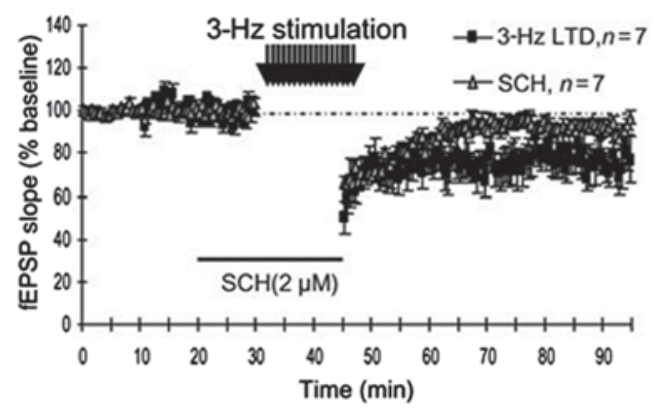

C

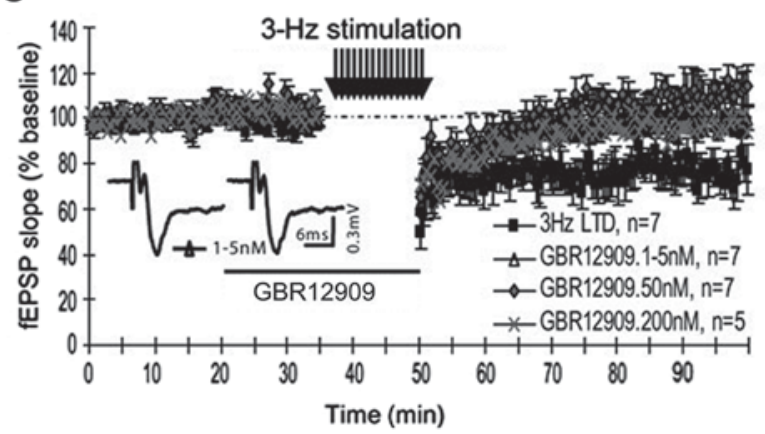

Fig. 4. Blockade of dopamine transporter activity impairs LTD induced by low-frequency repetitive stimulation. A. Delivery of single stimuli at $3 \mathrm{~Hz}$ (for $15 \mathrm{~min}$ ) to layer I-II presynaptic fibers induces stable LTD of the EPSP recorded extracellularly from layers I-II. The insets are the averaged EPSPs recorded just before (left) and $40 \mathrm{~min}$ after stimulation. Scales: vertical, $0.3 \mathrm{mV}$; horizontal, $6 \mathrm{~ms}$. B1. LTD induced by $3 \mathrm{~Hz}$ stimuli is blocked by the D1 antagonist SCH23390 (2 $\mathrm{mmol} / \mathrm{L})$ applied during stimulation (grey triangles). B2. LTD induced at $3 \mathrm{~Hz}$ is blocked by the D2 antagonist sulpiride ( $20 \mu \mathrm{mol} / \mathrm{L}$ ) applied during stimulation (grey circles). C. Augmentation of the extracellular dopamine level by bath-application of the DAT inhibitor GBR12909 (white triangles, 1-5 nmol/L; white diamonds, $50 \mathrm{nmol} / \mathrm{L}$; crosses, $200 \mathrm{nmol} / \mathrm{L}$ ) during LTD-inducing 3-Hz stimulation blocks the induction of LTD. The insets are averaged EPSPs recorded just before (left) and $40 \mathrm{~min}$ after stimulation (right) in the 1-5 nmol/L group. Adapted from Bai et al. (2014) ${ }^{[27]}$ with permission.

bath-applied during 3-Hz stimulation, significantly impairs LTD (Fig. 4C) ${ }^{[27]}$. This impairment appears to be due to an over-stimulation of D1 receptors, since counteracting D1 receptor stimulation by co-applying a low level of $\mathrm{SCH} 23390$ ( $1 \mu \mathrm{mol} / \mathrm{L})$ together with GBR12909 cancels the blocking action of GBR12909 on LTD ${ }^{[27]}$. Such blockade is not seen when a low level of sulpiride $(10 \mu \mathrm{mol} / \mathrm{L})$ is co-applied with GBR12909. Since $10 \mu \mathrm{mol} / \mathrm{L}$ sulpiride itself is insufficient to block LTD ${ }^{[27]}$, the persistent blockade of LTD with sulpiride + GBR12909 is not because the sulpiride blocked LTD; rather, it is likely that the D2 antagonist sulpiride does not counteract the LTD-blocking action of GBR12909 ${ }^{[27]}$.

Taken together, these results indicate that DA controls LTD induction also through an inverted-U dose-response manner. This dependency on DA appears to be critically determined by the level of D1 receptor stimulation.

\section{Molecular Mechanism of LTD Impairment by}

\section{Dopamine Transporter Inhibition}

What is the molecular mechanism of LTD impairment by DAT inhibition? According to our western blot analysis, it involves over-activation of ERK1/2, a class of messengers also necessary for LTD by $D^{[27]}$. First, ERK activity in the prelimbic area significantly increases in the LTDimpaired condition, i.e. $3-\mathrm{Hz}$ stimulation in the presence of GBR12909. This ERK increase is not seen when LTD impairment is blocked, i.e. when $\mathrm{SCH} 23390(1 \mu \mathrm{mol} / \mathrm{L})$ is copresent with GBR12909. Second, when the ERK increase seen with 3-Hz stimulation + GBR12909 is counteracted by simultaneous application of a low concentration of the ERK inhibitor PD98059 (5 $\mu \mathrm{mol} / \mathrm{L} ; 1 / 10$ of the $\mathrm{IC}_{50}$ value ${ }^{[32]}$ ), the 
LTD blockade by GBR12909 is also counteracted. Third, the allosteric positive modulator of mGluR5 (metabotropic glutamate receptor 5), CDPPB (3-cyano-N-(1,3-diphenyl$1 \mathrm{H}$-pyrazol-5-yl)benzamide), which we found cancels the impairment of LTD by GBR12909, also cancels the overactivation of ERK by GBR12909.

Thus, we suggest that over-stimulation of DA (D1) receptors during GBR12909 application leads to overactivation of ERK1/2, which results in LTD impairment. The detailed molecular mechanism as to how the ERK overactivation occurs and how it impairs LTD remains to be clarified. It is also still unknown how CDPPB downregulates ERK activity. In addition, the over-activation of ERK1/2 under hyper-dopaminergic conditions seems inconsistent with our earlier data showing that $10 \mu \mathrm{mol} / \mathrm{L}$ background DA does not increase ERK1/2 activity, while $3 \mu \mathrm{mol} / \mathrm{L}$ does. This inconsistency is currently unexplained, although it may be related to the difference between the bath application of background DA and its stimulus-evoked endogenous release. Whatever the case, over-activation of ERK1/2 has also been shown with cocaine intake in rodents ${ }^{[33]}$.

\section{LTD and Background Dopamine}

A major difference between LTP and LTD in our model system is that LTD can be induced even without background $\mathrm{DA}^{[27]}$. Functionally, this may indicate that the physiological role of LTD (suppression of old goal-directions ${ }^{[30]}$ ), persists even under extremely low levels of background DA. But under such a pathophysiological condition, LTP, unlike LTD, either cannot be induced (Fig. 1A) or converts to LTD (Fig. 1B). This latter LTD induced by LTP-inducing high-frequency stimulation under hypo-dopaminergic conditions should be termed "aberrant LTD" and separated from the physiological LTD induced by low-frequency stimulation. Aberrant LTD can be seen also with high-frequency stimulation in the presence of very high DA $(100 \mu \mathrm{mol} / \mathrm{L})^{[24,25]}$. Thus, when the concentration of background DA deviates greatly from the normal range, synaptic efficacy in the PFC neuronal network might be abnormally low.

\section{Conclusion}

Both LTP and LTD in rat PFC glutamatergic synapses show dependence on the DA level, characterized by the inverted-U shape function. LTP even converts to LTD if the background DA level is very low, as may occur in the PFC of chronically-stressed individuals or schizophrenic patients. Under these conditions, physiological LTD may still persist. As a result, synaptic efficacy in the PFC network might overly lower. The level of background DA may also be influenced by the emotional state, where acute aversive conditions appear to give rise to PFC extracellular DA levels more effectively than appetitive conditions ${ }^{[34-36]}$. Such an acute state may set the background DA at an optimal level to promote LTP, as shown in the hippocampus ${ }^{[37]}$, and this may lead to better memory encoding as known empirically.

On the other hand, the psychoactive drug cocaine may exaggerate the action of stimulus-evoked, phasic DA release and impair physiological LTD. This action may lead to an impaired behavioral flexibility. The positive allosteric modulator of mGluR5 may serve as a treatment option for this cocaine-induced rigid goal-direction.

Received date: 2014-06-15; Accepted date: 2014-11-18

\section{REFERENCES}

[1] Fuster JM. Memory in the Cerebral Cortex. Boston: A Bradford Book. The MIT Press, 1995.

[2] Goto Y, Yang CR, Otani S. Functional and dysfunctional synaptic plasticity in prefrontal cortex: roles in psychiatric disorders. Biol Psychiatry 2010, 67: 199-207.

[3] von Bohlen und Halbach O, Dermietzel R. Neurotransmiters and Neuromodulators. 2nd ed. Weinheim, Germany: WILEYVCH Verlag Gmbh \& Co., 2006.

[4] Lee SP, So CH, Rashid AJ, Varghese G, Cheng R, Lança AJ, et al. Dopamine D1 and D2 receptor co-activation generates a novel phospholipase-mediated calcium signal. J Biol Chem 2004, 279: 35671-35678.

[5] Seamans JK, Yang CR. The principal features and mechanisms of dopamine modulation in the prefrontal cortex. Prog Neurobiol 2004, 74: 1-57.

[6] Goto Y, Otani S, Grace AA. The Yin and Yang of dopamine release: a new perspective. Neuropharmacology 2007, 53: 583-587.

[7] Funahashi S. Space representation in the prefrontal cortex. Prog Neurobiol 2013, 103: 131-155.

[8] Lett TA, Voineskos AN, Kennedy JL, Levine B, Daskalakis ZJ. Treating working memory deficits in schizophrenia: a review of the neurobiology. Biol Psychiatry 2014, 75: 361-370.

[9] Barch DM, Dowd EC. Goal representations and motivational drive in schizophrenia: the role of prefrontal-striatal interactions. Schizophr Bull 2010, 36: 919-934.

[10] Touzani K, Puthanveettil SV, Kandel ER. Consolidation of learning strategies during spatial working memory task requires protein synthesis in the prefrontal cortex. Proc Natl 
Acad Sci U S A 2007, 104: 5632-5637.

[11] Keil A, Muller MM, Ray WJ, Gruber T, Elbert T. Human gamma band activity and perception of a gestalt. J Neurosci 1999, 19: 7152-7161.

[12] Gurden H, Tassin JP, Jay TM. Integrity of the mesocortical dopaminergic system is necessary for complete expression of in vivo hippocampal-prefrontal cortex long-term potentiation. Neuroscience 1999, 94: 1019-1027.

[13] Takahata R, Moghaddam B. Target-specific glutamate regulation of dopamine neurons in the ventral tegmental area. J Neurochem 2000, 75: 1775-1778.

[14] Matsuda Y, Marzo A, Otani S. The presence of background dopamine signal converts long-term depression to potentiation in rat prefrontal cortex. J Neurosci 2006, 26: 4803-4810.

[15] Kolomiets B, Marzo A, Caboche J, Vanhoutte P, Otani S. Background dopamine concentration dependently facilitates long-term potentiation in rat prefrontal cortex through postsynaptic activation of extracellular signal-regulated kinases. Cereb Cortex 2009, 19: 2708-2718.

[16] Roitman MF, Stuber GD, Phillips PE, Wightman RM, Carelli RM. Dopamine operates as a subsecond modulator of food seeking. J Neurosci 2004, 24: 1265-1271.

[17] Garris PA, Ciolkowski EL, Pastore P, Wightman RM. Efflux of dopamine from the synaptic cleft in the nucleus accumbens of the rat brain. J Neurosci 1994, 14: 6084-6093.

[18] Seamans J, Durstewitz D, Christie BR, Stevens CF, Sejnowski TJ. Dopamine D1/D2 receptor modulation of excitatory synaptic inputs to layer $\mathrm{V}$ prefrontal cortex neurons. Proc Natl Acad Sci U S A 2001, 98: 301-306.

[19] Chen L, Bohanick JD, Nishihara M, Seamans JK, Yang CR. Dopamine D1/5 receptor-mediated long-term potentiation of intrinsic excitability in rat prefrontal cortical neurons: $\mathrm{Ca2+-}$ dependent intracellular signaling. J Neurophysiol 2007, 97: 2448-2464.

[20] Schultz W. Multiple dopamine functions at different time courses. Annu Rev Neurosci 2007, 30: 259-288.

[21] Yagishita S, Hayashi-Takagi A, Ellis-Davies GC, Urakubo H, Ishii S, Kasai H. A critical time window for dopamine actions on the structural plasticity of dendritic spines. Science 2014 , 345: 1616-1620.

[22] Young CE, Yang CR. Dopamine D1-like receptor modulates layer and frequency-specific short-term synaptic plasticity in rat prefrontal cortical neurons. Eur J Neurosci 2005 21: 3310-3320.

[23] Van Eden CG, Hoorneman EM, Buijs RM, Matthijssen MA, Geffard M, Uylings HB. Immunocytochemical localization of dopamine in the prefrontal cortex of the rat at the light and electron microscopical level. Neuroscience 1987, 22: 849-862.

[24] Otani S, Blond O, Desce JM, Crépel F. Dopamine facilitates long-term depression of glutamatergic transmission in rat prefrontal cortex. Neuroscience 1998, 85: 669-676.
[25] Otani S, Auclair N, Desce JM, Roisin MP, Crépel F. Dopamine receptors and groups I and II mGluRs cooperate for long-term depression induction in rat prefrontal cortex through converging postsynaptic activation of MAP kinases. J Neurosci 1999, 19: 9788-9802.

[26] Huang YY, Simpson E, Kellendonk C, Kandel ER. Genetic evidence for the bidirectional modulation of synaptic plasticity in the prefrontal cortex by D1 receptors. Proc Natl Acad Sci U S A 2004, 101: 3236-3241.

[27] Bai J, Blot K, Tzavara E, Nosten-Bertrand M, Giros B, Otani S. Inhibition of dopamine transporter activity impairs long-term depression in rat prefrontal cortex through over-stimulation of D1 receptors. Cereb Cortex 2014, 24: 945-955.

[28] Morris SH, Knevett S, Lerner EG, Bindman LJ. Group I mGluR agonist DHPG facilitates the induction of LTP in rat prelimbic cortex in vitro. J Neurophysiol 1999, 82: 1927-1933.

[29] Sanchez CJ, Bailie TM, Wu WR, Liand N, Sorg BA. Manipulation of dopamine D1-like receptor activation in the rat medial prefrontal cortex alters stress- and cocaineinduced reinstatement of conditioned place preference behavior. Neuroscience 2003, 119: 497-505.

[30] Schmidt HD, Pierce RC. Systemic administration of a dopamine, but not a serotonin or norepinephrine, transporter inhibitor reinstates cocaine seeking in the rat. Behav Brain Res 2006, 175: 189-194.

[31] Nicholls RE, Alarcon JM, Malleret G, Carroll RC, Grody $\mathrm{M}$, Vronskaya $\mathrm{S}$, et al. Transgenic mice lacking NMDARdependent LTD exhibit deficits in behavioral flexibility. Neuron 2008, 58: 104-117.

[32] Alessi DR, Cuenda A, Cohen P, Dudley DT, Saltiel AR. PD 098059 is a specific inhibitor of the activation of mitogenactivated protein kinase kinase in vitro and in vivo. J Biol Chem 1995, 270: 27489-27494.

[33] Valjent E, Pagès C, Hervé D, Girault JA, Caboche J. Addictive and non-addictive drugs induce distinct and specific patterns of ERK activation in mouse brain. Eur $\mathrm{J}$ Neurosci 2004, 19: 1826-1836.

[34] Feenstra MGP, Teske G, Botterblom MHA, De Bruin JPC. Dopamine and noradrenaline release in the prefrontal cortex of rats during classical aversive and appetitive conditioning to a contextual stimulus: interference by novelty effects. Neurosci Lett 1999, 272: 179-182.

[35] Feenstra MGP. Dopamine and noradrenaline release in the prefrontal cortex in relation to unconditioned and conditioned stress and reward. Prog Brain Res 2000, 126: 133-163.

[36] Mingote S, de Bruin JP, Feenstra MG. Noradrenaline and dopamine efflux in the prefrontal cortex in relation to appetitive classical conditioning. J Neurosci 2004, 24: 2475-2480.

[37] Korz V, Frey JU. Bidirectional modulation of hippocampal long-term potentiation under stress and no-stress conditions in basolateral amygdala-lesioned and intact rats. J Neurosci 2005, 25: 7393-7400. 